\title{
Comparative study of estrogen receptor $\alpha, \beta$ mRNA expressions of endometriosis and normal endometrium in women and analysis of potential synthetic anti-estrogens in silico
}

\author{
Eldafira Eldafira, ${ }^{1,2}$ Abinawanto Abinawanto, ${ }^{1}$ Luthfiralda Sjahfirdi, ${ }^{1}$ Asmarinah Asmarinah, ${ }^{2}$ \\ Purnomo Soeharso, ${ }^{2}$ Muharam Muharam, ${ }^{3}$ Vivitri D. Prasasty, ${ }^{4}$ Dwi A. Pujianto ${ }^{2}$
}

${ }^{1}$ Department of Biology, Faculty of Mathematics and Natural Sciences, Universitas Indonesia; ${ }^{2}$ Department of Biology, Faculty of Medicine, Universitas Indonesia; ${ }^{3}$ Department of Obstetrics and Gynecology, RSCM; ${ }^{4}$ Faculty of

Biotechnology, Atma Jaya Catholic University of Indonesia, Jakarta, Indonesia

Correspondence: Abinawanto Abinawanto, Department of Biology, Faculty of Mathematics and Natural Sciences, Universitas Indonesia, Jl. Margonda Raya, 16424, Depok, Indonesia.

Tel.: +62.021.31930379 - Fax: +62.021.31907281.

E-mail: abinawanto.ms@sci.ui.ac.id

Key words: Estrogen receptor; mRNA expression; Endometriosis; Antiestrogens; Molecular docking.

Acknowledgments: the authors would like to thank Prof. Dr. Ichramsyah, Sp.OG (K), Prof. Dr. T.Z. Jakoeb, Sp.OG (KFER), Dr. R. Muharam, Sp.OG (K) who have been willing to provide an opportunity to help in the process of providing tissue samples from patients with endometriosis cases.

Contributions: the authors contributed equally.

Conflict of interest: the authors declare no potential conflict of interest.

Funding: this research was supported by personal funding and nonfinancial support from Department of Biology of Faculty of Mathematics and Natural Sciences; and Faculty of Medicine, Universitas Indonesia.

Clinical trials: the study was registered at the Committee of the Medical research Ethics of the Faculty of Medicine, Universitas Indonesia, Indonesia, with registered no. 165/PT02.FK/Etik/2010.

Dedication: the article is dedicated to Department of Biology, Faculty of Mathematics and Natural Sciences, Universitas Indonesia. It is also dedicated to Hospital of Mother and Child Budhi Jaya and SanMerri which gave dedicated consent to the patient to facilitate tissue sampling.

Received for publication: 8 May 2018.

Revision received: 16 September 2018.

Accepted for publication: 5 November 2018.

(C) Copyright E. Eldafira et al., 2018

Licensee PAGEPress, Italy

Journal of Biological Research 2018; 91:7550

doi:10.4081/jbr.2018.7550

This article is distributed under the terms of the Creative Commons Attribution Noncommercial License (by-nc 4.0) which permits any noncommercial use, distribution, and reproduction in any medium, provided the original author(s) and source are credited.

\begin{abstract}
Endometriosis is a multifactorial disease in which genetic and environmental factors interact causing its pathogenesis. The aim of this study was to investigate the expression pattern of estrogen receptor $\alpha(E R \alpha)$ and $\beta(E R \beta)$ in endometriosis patients compared to normal endometrioum $(\mathrm{n}=18)$ as a control by using Quantitative Real Time PCR method. Moreover, we also measured serum estradiol levels of endometriosis patients in the proliferation phase of the menstrual cycle using the enzyme-linked immunosorbent assay method. The mRNA expression of ER $\beta$ was significantly higher in the endometriosis group compared to control, and the result of $t$-test showed that were significantly different $(\mathrm{P}<0.05)$. Overexpression of ER $\beta$ in endometriosis was likely to have other significant important impacts in the pathology of endometriosis that allowed ER $\beta$ to stimulate prostaglandin production in endometriosis tissue and cells. Estradiol content did not correlate with the ER $\alpha$ expression, and it is weakly correlated with ER $\beta$ mRNA expression. Molecular docking analysis showed that ER $\alpha$ and ER $\beta$ have different binding interactions with synthetic antiestrogens, whereas the best inhibitor was Ral2 to ER $\alpha$ and Acol to ER $\beta$. Thus, both inhibitors could be used as leads in further investigation of $\mathrm{ER} \alpha, \mathrm{ER} \beta$ inhibitory activities in vitro and in vivo.
\end{abstract}

\section{Introduction}

Endometriosis is a chronic gynecological disease which manifested by tissue resembling endometrium and stroma that grows and develops outside the uterine cavity. ${ }^{1,2}$ The sites that are often the site of developing endometriosis tissue are pelvis and abdominal cavities. Currently, endometriosis is found in about $10-15 \%$ in women of childbearing age worldwide and even found also in adolescent girls. ${ }^{1}$

Endometriosis is characterized by clinical symptoms including chronic pelvic pain, dysmenorrhea (pain during menstruation), and deep dyspareunia (time-related pain). ${ }^{3}$ However, the etiology and pathophysiology of endometriosis is not fully understood. This is due to multifactorial endometriosis disease caused by various factors such as environment, immunology and genetics. ${ }^{4-6}$ Several studies have reported that endometriosis is strongly associated with estrogen hormone and found significantly higher in local tissue of endometriosis patients compared to normal 
endometrial tissue. ${ }^{4}$ High estrogen levels can stimulate the growth of lesions containing endometrial glands and stromal cells outside the uterine cavity, resulting pain and inflammation. ${ }^{5}$

Previous studies showed that in normal women, serum estradiol levels of proliferation phase were found approximately 491.64 $\mathrm{pmol} / \mathrm{L}$, normally within range between $103-1,731 \mathrm{pmol} / \mathrm{L}$, and the luteal phase has lower level than the proliferative phase. ${ }^{6}$ However, estradiol level of proliferation phase in patients with endometriosis is still unknown. ${ }^{\text {? }}$

The biological activity of estrogens is mediated by its specific estrogen receptor, so that changes in the quantity and affinity of these receptors can lead to pathological states. ${ }^{4}$ The association between estrogen and its receptor will affect the expression level of specific genes in the target cell. The results of previous studies reported that 100 times increasing estrogen receptor $\beta$ (ER $\beta$ ) expression in endometriosis tissue compared to normal endometrial tissue, and ER $\beta$ suppressed the expression of estrogen receptor $\alpha(\mathrm{ER} \alpha)$ in endometriosis tissue. However, the mechanism interaction between ERs and estradiol are not clearly understood. ${ }^{3}$

Therefore, this study aimed to determine the mRNA expressions of $E R \alpha$ and $E R \beta$ between endometriosis and normal endometrium in women, also characterize the estradiol levels on endometriosis patients. Furthermore, the structure-based relationship between ER receptors and ER inhibitors were also evaluated under molecular docking analysis. It has been known that the promising synthetic anti-estrogens could halt the proliferative effects of estrogen receptors on gynaecological pathologies of endometrial epithelial cells, causing endometriosis, infertility and endometrial cancer. ${ }^{8}$ Thus, therapeutic agents in treatment of gynaecological pathology such as endometriosis are required to compete with steroidal estrogens and antagonize ERs.

\section{Materials and Methods}

\section{Preparation of tissue samples}

Sampling was carried out after approval of the patients informed consent. The amount of tissue samples were $18(n=18)$ from normal endometrium (control group) and $18(\mathrm{n}=18)$ from endometriosis tissue (case group).

Control tissue samples were obtained by micro curettage technique (endometrial biopsy). The samples were taken from unexplained infertility female patients (aged from 18 to 45 years) without symptoms of endometriosis and endometrioma, in Sam Marie Family HealthCare Hospital. Subsequently, endometrial tissues were prepared as histological preparations, with aim to check whether the endometrial tissues visualized as same as normal endometrium at the phase before ovulation (starting on the 5th day after menstruation). This test was carried out by the obstetricians and by the Pathologic Anatomic examination, then part of the tissue was stored in RNA later at a freezer $-20^{\circ} \mathrm{C}$ to examine mRNA expression of ER in normal endometrium tissue.

The samples of case tissue from endometriosis patients were obtained by laparoscopic technique, for taking endometriosis tissue. Women patients (aged from 18 to 45 years) with endometriosis were examined by obstetricians from Cipto Mangunkusumo Hospital and Budhi Jaya Hospital. Endometriosis tissues were taken by laparoscopy as much as two centimeters, inserted into a microtube which contained RNA later, and stored in a freezer of $20^{\circ} \mathrm{C}$ for further mRNA isolation and cDNA synthesis.

\section{Measurement of serum estradiol level}

Examination of serum estradiol level was performed using DRG estradiol ELISA Kit EIA-2693. Standard solution used in this kit was set at concentrations of $0 ; 25 ; 100 ; 250 ; 500 ; 1000$ and $2000 \mathrm{pg} / \mathrm{mL}$, respectively. Estradiol concentration then determined by comparing the Optical Density value of the samples with the standard curve. Substrate was added, and the enzyme converted the substrate into chromogenic or fluorescent signals in competitive ELISA, the higher the concentration of the original antigen, the weaker the signal generated. ${ }^{9}$

\section{Isolation of RNA}

RNA kit reagent used was a High Pure RNA Isolation Kit version 12 (Roche). Approximately 18 RNA samples were isolated from tissue biopsy of endometriosis which is already stored in a later RNA of $0.1 \mathrm{~cm}$, then inserted into a cryo tube. The quantification of isolated RNA was carried out by measuring the concentration and purity of RNA in case and control groups using the drop nano metro tool. The purity of the isolated RNA is determined by absorbance ratio at 260/280 wavelengths against protein contamination and 260/230 for purity against salt, ethanol and phenol concentrations. The RNA solution (30 ng) was standardized before proceeding with cDNA synthesis process. ${ }^{10}$

\section{Synthesis of cDNA}

The cDNA synthesis was performed by Reverse Transcriptase (RT) PCR technique using Transcript First Strand cDNA Synthesis Kit by following its protocol (Roche). The solution concentration containing cDNA was further measured and its purity was checked using nano drop. The cDNA samples was stored at $-20^{\circ} \mathrm{C}$ for further analysis. ${ }^{11}$

\section{Amplification of cDNA fragment target}

Each sample was duplicated for each tested gene. First step, created a mixed solution of PCR by plotting the reaction component into plate/well with the composition: Taqman Fast Advanced Master Mix (2x) 10 $\mu \mathrm{L}$, Taqman Gene Expression Assay (20x) 1 $\mu \mathrm{L}, 2 \mu \mathrm{L}$ cDNA template, and nuclease free water $7 \mu \mathrm{L}$. Total volume of reaction is $20 \mu \mathrm{L}$ for 1 reaction. The plate was covered and vortexed then spun down to reduce air bubbles. Reaction profile conditions of RT-PCR were incubation stage at $50^{\circ} \mathrm{C}$ for 2 minutes, activation of polymerase at $95^{\circ} \mathrm{C}$ for 20 seconds, denaturation at $95^{\circ} \mathrm{C}$ for one second and annealing stage at $60^{\circ} \mathrm{C}$ for 20 seconds. The reaction was run for 40 cycles. The primers used in this expression study were GAPDH, ER $\alpha$ and ER $\beta .{ }^{12}$

\section{Statistical analysis}

The difference of gene expression values between endometriosis and control group in determining the value of target gene expression was obtained from the difference of Cycle Threshold (Ct) value of the target gene was subtracted by $\mathrm{Ct}$ reference gene. The relative expression value was determined using Livak method established by the formula $2^{-\Delta \Delta \mathrm{Ct}}$, whereas method that analyzes the relative changes of gene expression from a real time quantitative PCR experiment that compares between endometriosis and control patients. Statistical analysis begins with the normality test on each obtained data. The Mann-Whitney test was performed to determine the difference of estradiol and unpaired $\mathrm{T}$ test to analyze the expression data of ER $\alpha$ and ER $\beta$ mRNA between case and control group with $\mathrm{P}=0.05$. The correlation between estradiol levels with ER $\alpha$ and ER $\beta$ gene expressions were performed by Spearman's test $(\alpha=0.05)$. 
and raloxifene were parental ligands, while other nine ligands were raloxifene analogues with a chloride $(-\mathrm{Cl})$ atom substitution in its side chain (Figure 1). Pharmacokinetic properties of all eleven ligands were tested using Molsoft platform. ${ }^{16}$ In silico molecular docking analyses were done using Autodock Vina. The box size and central box of gridbox were set at specific directed coordinate site parameters. ${ }^{17}$

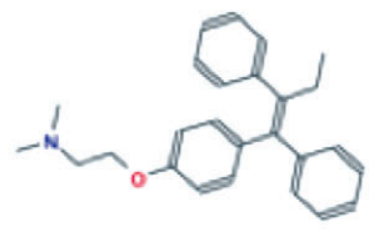

Tamoxifen<smiles>Oc1ccc(C2=C(Cl)c3ccc(O)cc3OC2c2ccc(OCCN3CCCCC3)cc2)cc1</smiles>

Aco2

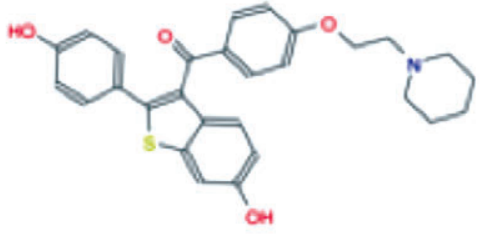

Raloxifene

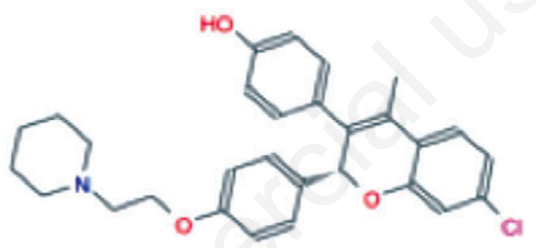

Aco3

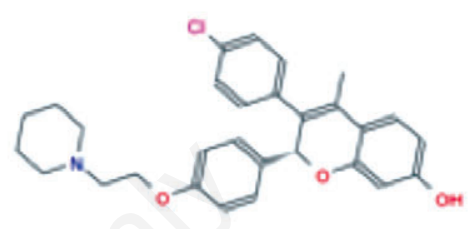

Aco 1

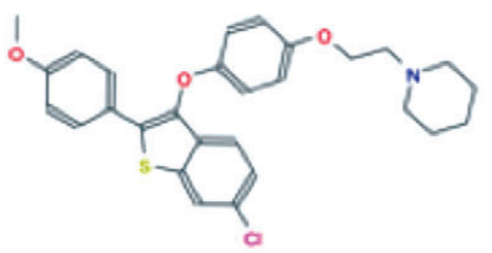

Arzl

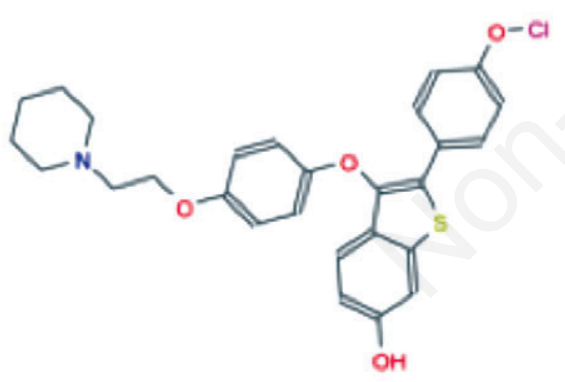

Arz2

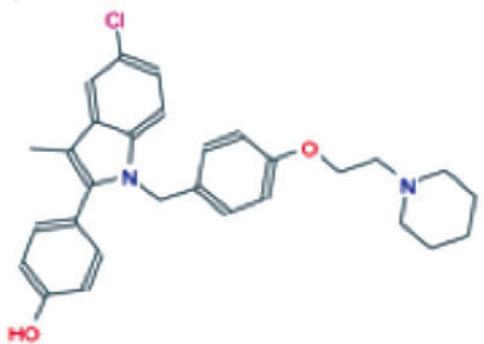

Bazl

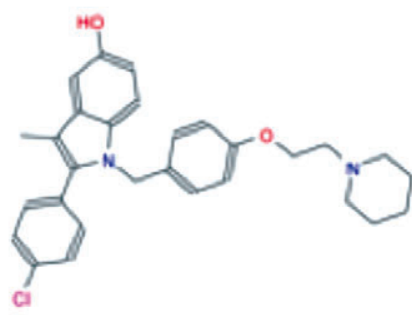

Baz2

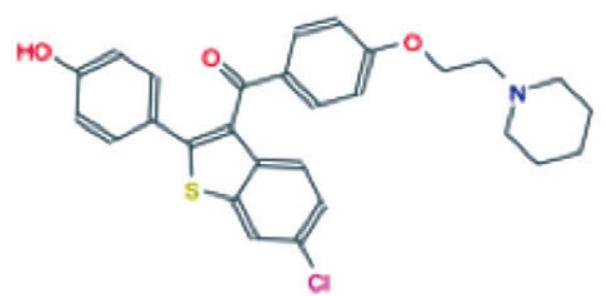

Ral1

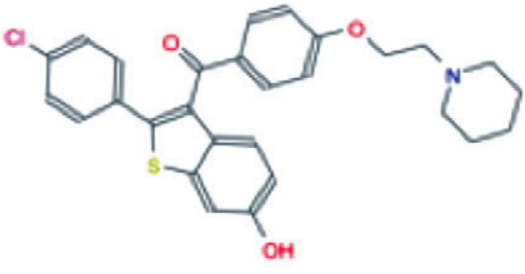

Ral2

Figure 1. The ligand structures of synthetic anti-estrogens: tamoxifen, raloxifene and nine raloxifene analogues, with - $\mathrm{Cl}$ substitutions in its side chain. 


\section{Results}

\section{ER $\alpha$ and ERß gene expression in case and control groups}

The relative gene expression values of $\mathrm{ER} \alpha$ and $\mathrm{ER} \beta$ were 0.33 and 49.52. Statistical test with t-test showed significantly difference between gene expression value of relative gene expression in control group and endometriosis group with $\mathrm{P}=0.00(\mathrm{P}<0.05)$. The result of $\mathrm{T}$ test between endometriosis case group and control group as shown in Table 1.

\section{Significance test of serum estradiol level on case and control groups}

The concentration of serum estradiol at proliferative phase was measured in all groups of endometriosis cases and controls to look at the effect of the highest estrogen levels on the menstrual cycle. Estrogen levels in women are affected by menstrual cycle conditions and maximal estrogen levels are at the time of the proliferation phase, which the peaks just before ovulation. ${ }^{18}$ The closer the blood sampling to the day of ovulation, the higher the serum estrogen levels. Estrogen concentrations between case and control groups showed that endometriosis group was higher than control group with median values were 86.35 (within the range 36.00 $598.60) \mathrm{pg} / \mathrm{mL}$ and 75.4 (within the range 22.31-159.52) $\mathrm{pg} / \mathrm{mL}$, respectively. Result of normality test of estradiol level data between both groups showed that the data in case group was not normally distributed while the data was normal distribution with $\mathrm{P}$ $>0.05$ in control group.

The results of this test indicated that the difference of serum estradiol levels in the endometriosis (case) and control group was not different significantly with the $\mathrm{P}=0.279(\mathrm{P}>0.05)$ as shown on Table 2.

\section{Correlation of estradiol level between ERa and ER $\beta$ expression in case group}

The correlation of serum estradiol levels with ER $\alpha$ and ER $\beta$ expressions can be seen from Spearman's correlation test (Table 3). The result showed that estradiol was not correlated with ER $\alpha$ expression, $\mathrm{P}=0.699(\mathrm{P}>0.05)$ as well as estradiol was also not correlated with $\mathrm{ER} \beta$ expression, $\mathrm{P}=0.570(\mathrm{P}>0.05)$.

\section{Pharmacophore and molecular docking prediction}

A predictive QSAR model was determined using Molsoft platform to evaluate the variation pharmacophore of selective antiestrogens (Table 4). The physicochemical properties of 11 antiestrogens were analyzed following Lipinski's rule. All eleven compounds were found 1 violations. In general, all compounds still followed Lipinski's rule, whereas each compound only has less than 3 violations.

In molecular docking results, the ligand binding domain of both ERs are mainly inside a hydrophobic cavity composed of residues that responsible in stabilizing the binding interactions. ${ }^{19}$ The best docked conformation of anti-estrogen within the ligand binding domain of ER $\alpha$ was Ral2 $(-9.9 \mathrm{kcal} / \mathrm{mol})$. Meanwhile, the best docked conformation of anti-estrogen within the ligand binding domain of ER $\beta$ was Acol $(-7.1 \mathrm{kcal} / \mathrm{mol})$ as shown in Table 4.

Further study is required to better understand the interaction of anti-estrogens with the residues of estrogen receptors will open up the possibility of using anti-estrogens for endometriosis treatment. The docked complex structures were visualized by $\mathrm{Pymol}^{20}$ (Figure 2A-B). The synthetic anti-estrogen structures were selected based on structural similarity with steroid-like backbones containing a tertiary amine on a side chain. It was proven that selected anti-estrogens bound to the same site on ER cavities as estrogen according to superimposed on ER $\alpha$ and $\operatorname{ER} \beta$ crystallographic structures.

Table 1. Relative mRNA expressions of ER $\alpha$ and ER $\beta$ in case and control groups.

\begin{tabular}{lccc} 
Gene & Group & Relative expression in $2^{-\Delta \Delta c t}$ & 0.13 \\
ER & Case & $0.33(0.25-0.48)$ & \\
ER & Control & $1(0.54-1.84)$ & 0.00 \\
& Case & $49.52(32.67-75.58)$ & $1(0.65-1.53)$ \\
\hline
\end{tabular}

Ct, cycle threshold; SE, standard error.

Table 2. Mann-Whitney test of serum estradiol levels on case and control groups.

\begin{tabular}{lcccc} 
Subject & Group $(\mathrm{n})$ & Median $(\mathrm{pg} / \mathrm{mL})$ & Min.-Max. value of median & P $<0.05$ \\
Case & 18 & 86.35 & $36.00-598.60$ & 0.279 \\
Control & 18 & 75.47 & $22.31-159.52$ & \\
\hline
\end{tabular}

Table 3. Spearman's correlation coefficient of serum estradiol level between ER $\alpha$ and ER $\beta$ expressions.

\begin{tabular}{lccc} 
Subject & Group $(\mathrm{n})$ & Regression value & P-value \\
Serum estradiol & 18 & & 0.699 \\
ER $\alpha$ expression & 18 & 0.098 & 0.570 \\
\hline ERß expression & 18 & -0.143 & \\
\hline
\end{tabular}


The interaction forces between anti-estrogens and estrogen receptors were plotted using the Ligplot program (Figure $2 \mathrm{C}-\mathrm{D}){ }^{21}$ Our results suggest that intermolecular hydrophobic interactions, hydrogen bonds and hydrogen bond radius $(\AA)$ were essential for the stability of estrogen receptor complexes. As visually evident from Figure 2C, the best docked conformation of Ral2 interacted with the residues surrounding ER $\alpha$ cavity site through intermolecular hydrophobic interactions including Leu346, Thr347, Ala350, Asp351, Glu353, Leu354, Trp383, Leu391, Phe404, Met421, Ile424, Phe425, Leu438, His524, Leu525 and Leu536. In the case of ER $\beta$, Acol contributed intermolecular hydrophobic interactions surrounding ER $\beta$ residues, involved Ser333, Arg466, His467, Asn470, Lys471, Met473 and Glu474 (Figure 2D). Moreover, two hydrogen bonds contributed to greater stabilize the interaction between oxygen atom from hydroxyl groups $(-\mathrm{OH})$ at side chain of Leu387 and Arg394 residues of ER $\alpha$ within radius $3.04 \AA$ and 3.25 $\AA$, respectively (Figure $2 \mathrm{C}$ ). Meanwhile, ER $\beta$ was also stabilized by two hydrogen bond which contributed from oxygen atom from $-\mathrm{OH}$ group of Glu387 and Ser 469 of ER $\beta$ side chain residues within radius $3.01 \AA$ and $3.88 \AA$, respectively (Figure $2 \mathrm{D}$ ).

\section{Discussion}

The main novelty of our study is to determine ER $\alpha$ and ER $\beta$ expressions on estrogen-responsive tissue of endometrium at proliferation phase. One of pathological effects of estrogen receptors in hormone-responsive endometriosis is to promote estrogen-stimulated cell proliferation in endometriosis remained to be evaluated. However, the relationship between estrogen hormone as well as serum estradiol levels from endometriosis groups versus control groups in the menstrual cycle at proliferation phase was still unknown. Previous studies have suggested that there are several factors that contribute to increased levels of local estradiol in endometrial tissue, among others, such as environmental toxins (dioxins) may have implications in the etiology of endometriosis that mimics estrogen and interact with its receptors. ${ }^{22}$ In addition, the bioavailability of estradiol in endometriosis tissue is due to the presence of local aromatase from circulating androgens to estradiol by endometriosis stromal cells ${ }^{23}$ resulting the decreased estradiol conversion to estrone due to reduction of 17ß-hydroxysteroid enzyme expression in endometriosis tissue affecting the increased local estradiol levels. ${ }^{24-26}$

The cause of increased estradiol in endometriosis tissue compared to normal molecular endometrium was due to serum estradiol entered the cell cytoplasm and bound to the receptor in the cell nucleus, the estrogen receptors eventually bound to the target gene in the promoter area. Hence, recruiting protein activator play a critical role in the activation of the transcription process. It can increase the expression of the estradiol receptor gene that is influential in cell physiological changes including pathological symptoms of endometriosis. ${ }^{4}$ The expression of steroid receptors and other nuclear receptors may differ between endometriosis and normal endometrial tissue. Previous study reported that the ER $\beta$ expression reached 100 times higher in eutopic endometriotic tissue than stromal cells in endometrial tissues that obtained from the same patients. The increased ER $\beta$ expression promoted ER $\beta$ in regulating cell cycle progression and it might contribute to proliferation of endometriotic stromal cells, which induced response to significant serum estradiol levels. ${ }^{6}$

In our study, the relative expression value of mRNA ER $\beta$ in endometriosis was 49 times higher than the control group. We emphasized here that our study used tissues from control groups of women which were different from the case group. The control group was normal non-endometriosis women who were unexplained infertility patients, which the tissues were obtained by endometrial micro curettage technique and kept as histological preparations. In histological preparations, the general structure of endometrial tissue was observed before ovulation, the tissues were visualized under microscope to check similarity form with normal endometrial tissue. Tissue and blood samples from control group were taken on day 8 to 11 after menstruation as same time as case group. The advantage of this study was that control tissues and case tissues were taken from different group have clearly resulted no significant effect of serum estradiol levels.

As reported in this study, ER $\beta$ expression could suppress ER $\alpha$ expression, by showing high ratio of ER $\beta / E R \alpha$ in endometriosis tissue. It promoted ER $\beta$ dominantly bound stronger to estrogen in the target tissue. Previous study explained that, ER $\beta$ expression

Table 4. Pharmacophore properties of anti-estrogens following Lipinski's rule of five with Molsoft and molecular docking analysis of ER $\alpha$ and ER $\beta$ with synthetic anti-estrogens.

\begin{tabular}{|c|c|c|c|c|c|c|c|c|c|}
\hline $\begin{array}{l}\text { Compound } \\
\text { Name }\end{array}$ & HBA & HBD & MW & $\log P$ & $\begin{array}{l}\text { Rotatable } \\
\text { Bonds }\end{array}$ & $\begin{array}{c}\text { MolPSA } \\
\left(A^{2}\right)\end{array}$ & $\begin{array}{l}\text { Violation of } \\
\text { R05 }\end{array}$ & \multicolumn{2}{|c|}{$\begin{array}{l}\text { Affinity Binding } \\
\text { (kcal/mol) }\end{array}$} \\
\hline Tamoxifen & 2 & 0 & 371.22 & 6.51 & 0 & 10.98 & 1 & -9.6 & -5.6 \\
\hline Raloxifene & 6 & 2 & 473.17 & 6.56 & 0 & 60.54 & 1 & -8.1 & -6.9 \\
\hline Acol & 4 & 1 & 475.19 & 7.86 & 1 & 36.04 & 1 & -8.9 & -7.1 \\
\hline Aco2 & 5 & 2 & 477.17 & 7.12 & 1 & 53.66 & 1 & -9.0 & -6.7 \\
\hline Aco3 & 4 & 1 & 475.19 & 7.86 & 1 & 36.04 & 1 & -8.3 & -5.9 \\
\hline Arzl & 5 & 0 & 493.15 & 8.06 & 0 & 26.31 & 1 & -7.8 & -5.8 \\
\hline Arz2 & 6 & 1 & 495.13 & 7.14 & 0 & 43.20 & 1 & -7.6 & -6.0 \\
\hline Bazl & 3 & 1 & 474.21 & 7.42 & 0 & 28.94 & 1 & -7.8 & -6.2 \\
\hline Baz2 & 3 & 1 & 474.21 & 7.42 & 0 & 28.94 & 1 & -7.7 & -6.2 \\
\hline Rall & 5 & 1 & 491.13 & 7.53 & 0 & 42.93 & 1 & -8.1 & -6.5 \\
\hline Ral2 & 5 & 1 & 491.13 & 7.53 & 7.53 & 42.93 & 1 & -9.9 & -6.4 \\
\hline
\end{tabular}

HBA, hydrogen bond acceptor; HBD, hydrogen bond donor; MW, molecular weight; Log P, partition coefficient logarithm; MolPSA, molecular polar surface area. 
was high in endometriotic stromal cells which suppressed ER $\alpha$ expression in endometriosis, resulting low progesterone receptor (PR), especially PR B, causing a tendency to lose paracrine signals. PR deficiency may result the decreased PR ability in binding to progesterone. Thus, only a small amount of progesterone can be synthesized, affecting the possibility of progesterone resistance in endometriosis patients. ${ }^{6}$

This mechanism may explain severe PR B deficiency in endometriotic tissues that contribute to progesterone resistance in women with endometriosis. Overexpression of ER $\beta$ in endometriosis is likely to have other significant important impacts in the pathology of endometriosis that allows ER $\beta$ to stimulate prostaglandin production in endometriosis tissue and cells, by inducing cyclooxygenase- 2 expression. ${ }^{6}$ Therefore, ER $\beta$ can be used as a key target of therapy for pain relieve associated with endometriosis. The selective compounds toward ER $\beta$ can be used as a treatment for endometriosis in the future. ${ }^{27}$ Expression of ERo and protein levels are several times lower in endometriotic stromal cells than in endometrial stromal cells. ER $\alpha$ deficiency in endometriosis can be responsible for the defect of estradiol to induce expression of progesterone. Thus, it was potentially contributing to secondary progesterone shortage and progesterone resistance in women with endometriosis. Previous study reported that estradiol also plays a key role in the regulation of ER $\alpha$ expression in human endometrial stromal cells due to high quantity of estradiol produced by local aromatase activity. In addition, high ER $\beta$ levels in endometriosis stromal cells may suppress the expression of ER $\alpha{ }^{26,27}$

It has been known that research in genetics has been carried out on endometriosis in several countries, and we have previously
A
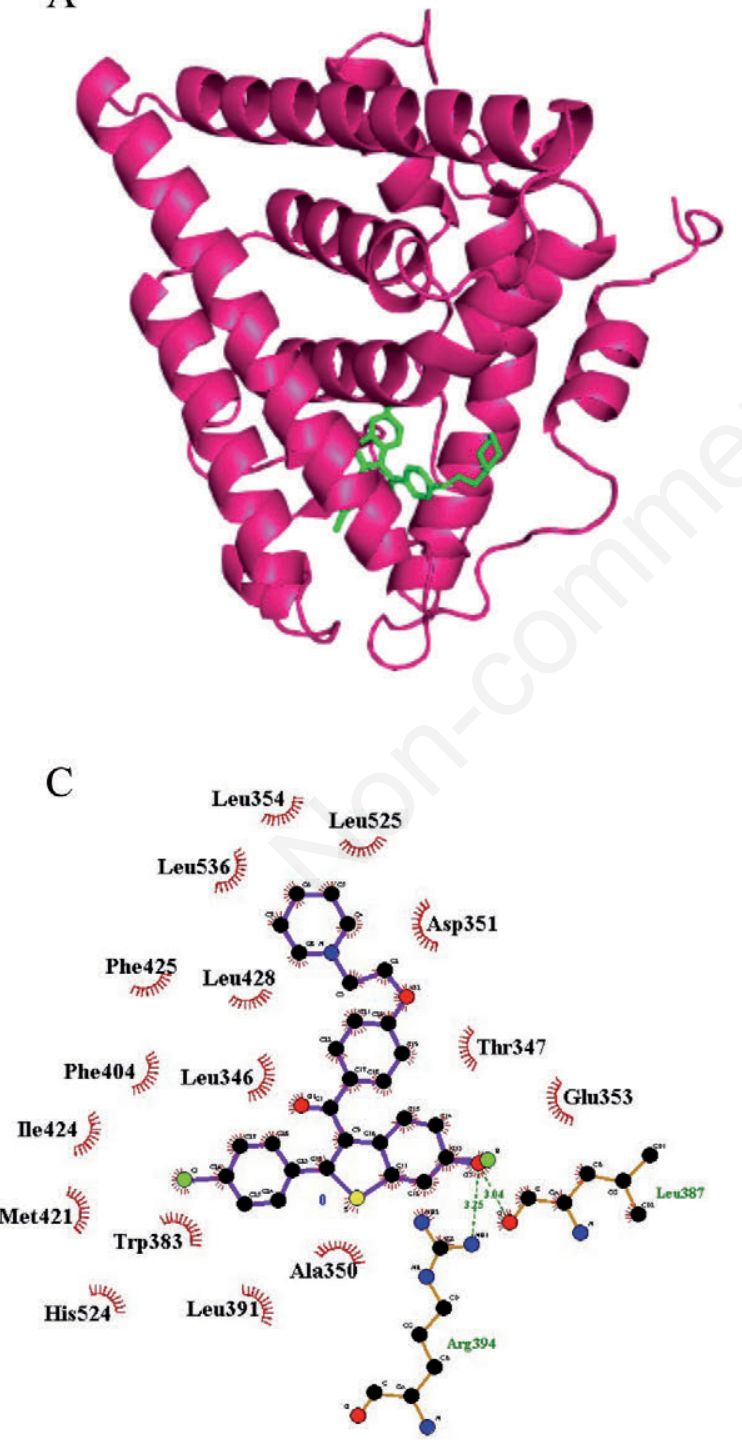

B

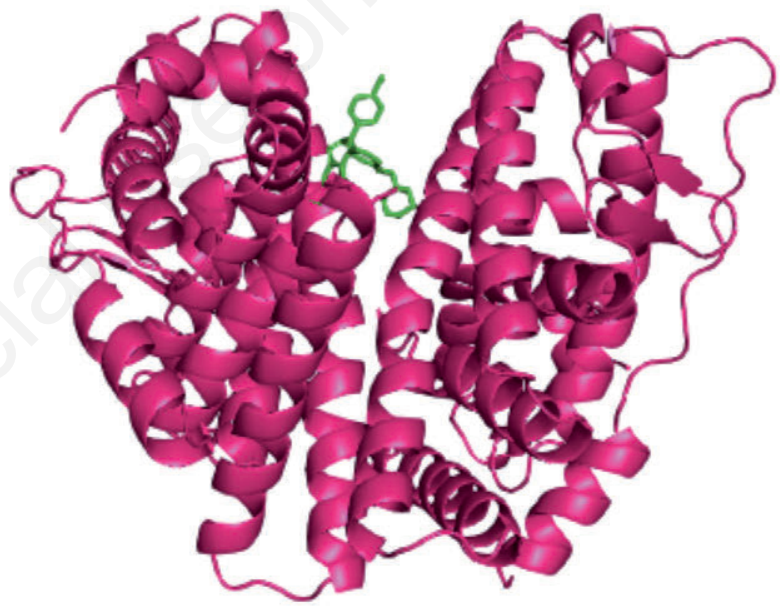

D

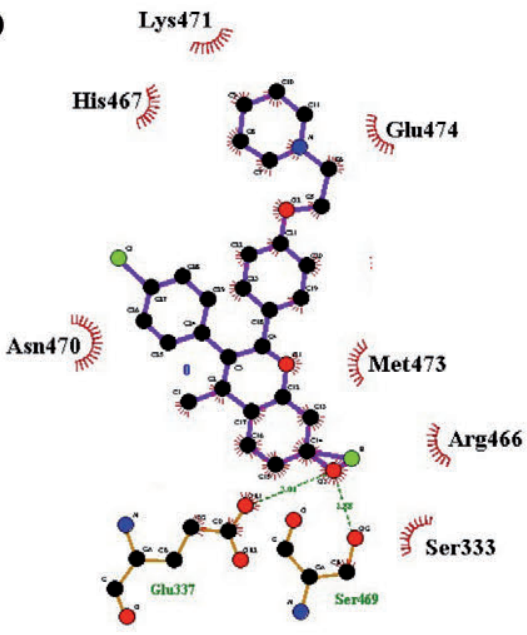

Figure 2. Molecular docking analysis according to the best binding interactions: (A) ERa (magenta) superimposed with Ral2 (green); (B) ERß (magenta) superimposed with Aco1 (green); (C) binding interaction between ER $\alpha$ residues with Ral2; (D) binding interaction between ER $\beta$ residues with Aco1. 
carried out comprehensive studies ranging from ER $\alpha$ and ER $\beta$ gene polymorphisms (data not shown). In this study, we proceed with studies of ER $\alpha$ and ER $\beta$ expression in endometriosis in relation with individual estradiol hormone levels. Previous studies have suggested that there was an effect of ER or allele gene polymorphisms on endometriosis abnormalities that produced different responses between countries or races. Previous studies reported that differences in the effect of gene significance or individual alleles on the response of endometriosis abnormalities. ${ }^{29,30}$ In some Asian countries, including Japan, the influence of polymorphism on endometriosis disorders has also been investigated. Therefore, we determined $E R \alpha$ and $E R \beta$ expressions in endometriosis patients in Indonesia. In addition, the weakness of pathological case studies of endometriosis in general, was difficult to distinguish between endometriosis tissue and normal endometrial tissue. ${ }^{29}$

The comprehensive approach that we have done became more interesting, due to our concerns in the treatment or therapy solution toward endometriosis. Generally, the treatment of drug administration in the case of endometriosis cannot be done on the right target, due to the administration of drugs decreased the estrogen levels, often causing risks to other organs that are strongly associated with estrogen levels in women, such as uterus, breast or other organs associated with the estrogen hormone. ${ }^{28}$ In this study, we attempted to find lead compounds that can act right on target as docking to be able to block ER $\alpha$ and $\operatorname{ER} \beta$.

The existing of two ER subtypes: ER $\alpha$ and ER $\beta$ have distinct tissue expression patterns and ligand specificities. ${ }^{28}$ Selective ligands such as anti-estrogens could mediate their biological effects by binding ER $\alpha$ and ER $\beta$ genes have shown positive effects in treatment of endometriosis. In order to provide a better therapy for such disease, a future potent generation of selective estrogen receptor modulators is required. It has been known that even only minor modifications of ER inhibitors can influence the selectivity of their binding. Thus, molecular docking was applied to investigate the structural basis of diverse selectivity and binding affinity of competitive ER $\alpha$ and ER $\beta$ inhibitors. Docking simulations revealed that estrogen competitors were potential in determining favorable binding affinity of both ER $\alpha$ and ER $\beta$ targets. In addition, molecular analyses in the greater stability related to greater docking score of the best docked-conformation ligand in the active site of the ER $\alpha$ and ER $\beta$ can be explained mainly by the presence of several important intermolecular forces, including hydrophobic interactions and hydrogen bond. The side substituents of emphasized molecular scaffold inside characterized cavities should be adopted in order to serve selectivity.

Moreover, the size and the electronic properties of the ligand substituents dramatically affect ER $\alpha$ and ER $\beta$ selectivities. Ral2 and Aco1 were selected ligands which showed the best inhibition of $E R \alpha$ and $E R \beta$, respectively. It has been reported that raloxifene analogues were being more potent than tamoxifen on inhibition of human mammary carcinoma cell proliferation and on decreasing rat uterine wet weight, ${ }^{4}$ by retaining $76 \%$ of the effectiveness of tamoxifen at reducing invasive breast cancer incidence with a significantly lower incidence of endometrial cancer in the Study of Tamoxifen and Raloxifen prevention trial. However, it is not effective in patients resistant to tamoxifen. the raloxifene analogue arzoxifene, despite being more potent than tamoxifen on inhibition of human mammary carcinoma cell proliferation and on decreasing rat uterine wet weight, but not as efficacious as tamoxifen in a comparative phase III clinical trial. It was also partially cross-resistant with tamoxifen in xenograft models. ${ }^{28}$ Thus, finding more effective anti-estrogens from raloxifene analogues are important. These molecular features should be considered during the discov- ery and design of potent $\mathrm{ER} \alpha$ and $\mathrm{ER} \beta$ inhibitors in remedy purpose of endometriosis disease. The docking results were expected can be useful in providing rational drug design as anti-estrogens, especially in phyto-pharmacy fields. ${ }^{28}$ Thus, these anti-estrogens can be more targeted to block ER $\alpha$ and $E R \beta$, and can minimize the risk of side effects on other organs related to estrogen hormone in the human body, especially women.

\section{Conclusions}

The ER $\beta$ expression was significantly higher in the endometriosis group than in controls. Similar to previous study, which explains that there were several mechanisms caused higher ER $\beta$ levels in endometriosis tissue than normal endometrium. Overexpression of ER $\beta$ in endometriosis is likely to have other significant important impacts in the pathology of endometriosis that allows ER $\beta$ suppressed ER $\alpha$ expression and stimulated prostaglandin production in endometriosis tissue and cells. Therefore, ER $\beta$ can be used as a key target of therapy for pain associated with endometriosis. Moreover, in silico approaches were applied to address the impact of structural stability on selective binding of the best docked conformation of tamoxifen to ER $\alpha$ and estradiol to ER $\beta$. It is expected that these findings could provide significant insights into ER-based drug development, in particular receptor-mediated mechanism upon endometriosis treatment.

\section{References}

1. Bouquet De Joliniere J, Ayoubi JM, Gianaroli L, et al. Endometriosis: a new cellular and molecular genetic approach for understanding the pathogenesis and evolutivity. Front Surg 2014;1:16.

2. Macer ML, Taylor HS. Endometriosis and infertility: a review of the pathogenesis and treatment of endometriosis-associated infertility. Obstet Gynecol Clin North Am 2012;39:535-49.

3. Harada T. Dysmenorrhea and endometriosis in young women. Yonago Acta Med 2013;56:81-4.

4. Rahmioglu N, Montgomery GW, Zondervan KT. Genetics of endometriosis. Womens Health (Lond) 2015;11:577-86.

5. Dun EC, Taylor RN, Wieser F. Advances in the genetics of endometriosis. Genome Med 2010;2:75.

6. Bulun SE, Cheng YH, Pavone ME, et al. Estrogen receptor- $\beta$, estrogen receptor- $\alpha$, and progesterone resistance in endometriosis. Semin Reprod Med 2010;28:36-43.

7. Bloski T, Pierson R. Endometriosis and chronic pelvic pain: unraveling the mystery behind this complex condition. Nurs Womens Health 2008; 12:382-95.

8. Silva CP, Lima DL, Schneider RJ, et al. Development of ELISA methodologies for the direct determination of 17betaestradiol and 17alpha-ethinylestradiol in complex aqueous matrices. J Environ Manage 2013;124:121-7.

9. Renner SP, Strick R, Oppelt P, et al. Evaluation of clinical parameters and estrogen receptor alpha gene polymorphisms for patients with endometriosis. Reproduction 2006;131:153-61.

10. Hapangama D, Kamal A, Bulmer J. Estrogen receptor $\beta$ : the guardian of the endometrium. Human Reproduct Update 2014;131:174-93.

11. Estradiol ELISA DRG instruments GmbH; 2010. Available 
from: http://www.drg-diagnostics.de/44-1-DRG+ELISAs.html? ItemPage $=4$

12. Roche High Pure RNA isolation Kit; 2011. Available from: https://lifescience.roche.com/documents/High-Pure-RNAIsolation-Kit.pdf

13. Roche Transcriptor first strand cDNA synthesis Kit; 2010. Available from: http://www.dynebio.co.kr/yc/shop/dw.php?fn $=1402000958 \% 2 F 04379012001$ cDNA.pdf

14. Applied Biosystems TaqMan Gene expression Assays; 2010. Available from: https://tools.thermofisher.com/content/sfs/ manuals/cms_041280.pdf

15. Berman HM, Westbrook J, Feng Z, et al. The protein data bank. Nucl Acid Res 2000;28:235-42.

16. Gao YD, Huang JF. An extension strategy of Discovery Studio 2.0 for non-bonded interaction energy automatic calculation at the residue level. Dongwuxue Yanjiu 2011;32:262-6.

17. Kim S, Thiessen PA, Bolton EE, et al. PubChem Substance and Compound databases. Nucl Acid Res 2016;44:D1202-13.

18. James T, Hsieh ML, Knipling L, et al. Determining the architecture of a protein-DNA complex by combining FeBABE Cleavage Analyses, 3-D Printed Structures, and the ICM Molsoft Program. Methods Mol Biol 2015;1334:29-40.

19. Trott O, Olson AJ. AutoDock Vina: improving the speed and accuracy of docking with a new scoring function, efficient optimization, and multithreading. J Comput Chem 2010;31:455-61.

20. Reed BG, Carr BR. The normal menstrual cycle and the control of ovulation. South Dartmouth, MA: MDtext.com; 2000.

21. Muchtaridi M, Syahidah HN, Subarnas A, et al. Molecular docking and 3D-pharmacophore modeling to study the interactions of Chalcone derivatives with estrogen receptor Alpha. Pharmaceuticals (Basel) 2017;10.

22. Seeliger D, de Groot BL. Ligand docking and binding site analysis with PyMOL and Autodock/Vina. J Comput Aided Mol Des 2010;24:417-22.

23. Wallace AC, Laskowski RA, Thornton JM. LIGPLOT: a program to generate schematic diagrams of protein-ligand interactions. Protein Eng 1995;8:127-34.

24. Vercellini P, Vigano P, Somigliana E, et al. Endometriosis: pathogenesis and treatment. Nat Rev Endocrinol 2014;10:261-75.

25. Bulun SE, Lin Z, Imir G, et al. Regulation of aromatase expression in estrogen-responsive breast and uterine disease: from bench to treatment. Pharmacol Rev 2005;57:359-83.

26. Cui J, Shen Y, Li R. Estrogen synthesis and signaling pathways during aging: from periphery to brain. Trends Mol Med 2013;19:197-209.

27. Bombail V, MacPherson S, Critchley HO, et al. Estrogen receptor related beta is expressed in human endometrium throughout the normal menstrual cycle. Hum Reprod 2008;23:2782-90.

28. Traboulsi T, El Ezzy M, Gleason J, et al. Antiestrogens: structure activity relationships and use in breast cancer treatment. J Molecul Endocrinol 2016;58:15-31.

29. Tsampazis N, Daniilidis A, Mavromichali M, et al. An overview of pathogenesis and pathophysiology in endometriosis. Curr Women's health Rev 2012;8:112-20.

30. Paul JQ, der Linden V. Theories on the pathogenesis of endometriosis. Eur Soc Hum Reprod Embryol 1996;11:53-63. 